\section{(6) OPEN ACCESS}

PAPER

\title{
How to keep high-risk studies ethical: classifying candidate solutions
}

\author{
Nir Eyal
}

\section{Correspondence to}

Professor Nir Eyal, Department

of Global Health and

Population, Harvard TH Chan

School of Public Health,

Harvard University, 02115

Boston, MA, USA;

neyal@hsph.harvard.edu

Received 1 February 2016

Accepted 18 February 2016

Published Online First

10 June 2016

\section{SLinked}

- http://dx.doi.org/10.1136/ medethics-2016-103416

CrossMark

To cite: Eyal N. J Med Ethics 2017;43:74-77.

\section{ABSTRACT}

This article lays out a wide spectrum of candidate ethical solutions for the challenge on which this JME symposium focuses: the benefit:risk ratio challenge to some early-phase HIV cure and remission studies. These candidate solutions fall into four categories: ones that seek to reduce risks in early-phase HIV cure and remission studies, ones that enhance the benefits for these studies' participants (or show that those were adequate in the first place), ones that focus on participants' free and informed consent to participate and ones according to whom the large benefits to nonparticipants can defeat considerations about individual participant net risks. In so doing, this article also structures the rest of the symposium.

\section{THE CHALLENGE}

Contributions to this JME symposium address an ethical challenge to some of the planned, ongoing and completed early-phase HIV cure and long-term remission trials. Some such studies place HIV-infected participants on regimens that involve high or highly uncertain risk (or specific procedures that are clinically unnecessary yet risky, burdensome or invasive). Early-phase trial participation usually offers little or no chance of being cured or of entering long-term remission. Even if it did (potentially with side effects from the curative intervention), medically this might not be superior enough to make the 'gamble' worthwhile compared with the alternative: remaining stable on antiretroviral treatment (ART), or at least so the challenge goes.

While most cure and remission studies permit patients to continue to take ART while the virus is detectable, do stable HIV patients gain from risky study participation in the first place? If not, is it ethical to recruit them for such trials? Doesn't their recruitment violate a putative ethical requirement for a favourable benefit:risk ratio in clinical research $^{1-3}$ often interpreted as requiring such a ratio for each study participant? ${ }^{4}$ Might it violate other ethical requirements?

We now lay out a wide spectrum of candidate solutions to this challenge, classified into four categories: candidate solutions that seek to reduce risks in early-phase HIV cure and remission studies, ones that enhance the benefits for study participants (or show that benefits were large enough in the first place), ones that focus on participants' free and informed consent to participate and ones according to which the large benefits to nonparticipants can defeat considerations about individual participants. In the course of mapping the conceivable candidate solutions, the present article finds occasion to describe the various contributions to this special JME symposium.

The article espouses or rejects none of the candidate solutions mapped and none of the other contributions to this symposium-including highly provocative ones and ones that strike as unethical. It mentions all in order to be comprehensive, and widen and deepen conversations in philosophical research ethics.

\section{RISKS}

The first solution to a concern about an adverse benefit:risk ratio is reducing the risk. There are many medical and administrative ways to try to keep the risk (and the personal burden or loss) in HIV cure and remission studies relatively low. Legal scholar and bioethicist Rebecca Dresser's contribution to this symposium expounds several, focusing on the case of HIV cure studies that are first-in-human. One move in that spirit is decreasing the risk to study participants by proceeding to human experimentation only after additional, and more rigorous, non-human animal studies, lab tests and mathematical modelling. ${ }^{5-9}$ Another is to limit (if possible) the cure intervention's dosage (or its frequency and toxic nature), so as to reduce the chance for adverse events, or to escalate dosage with overdose control-as is practiced in many early-phase cancer studies. ${ }^{10-14}$ A third candidate solution is developing firmer study safeguards such as explicit contingency plans for adverse events, including, in cure and remission studies, guidelines for ART discontinuation and restarting if needed. ${ }^{15}$ A fourth one is to defer experimenting with riskier cure strategies or wait for the development of safer alternatives to their relatively toxic components of cure interventions (such as immunosuppressive drugs), ${ }^{16}$ starting instead with other cure and remission strategies. A fifth one is observing precedents created by fluke or inappropriate care, as may have happened in some cases ${ }^{17}$ instead of intervening. A sixth is to involve the patient community in design or oversight in the hope that this would bolster safety. ${ }^{18} 19$

A final candidate solution in this category is avoiding or deferring early-phase trials on physically or socially vulnerable populations, such as patients with advanced HIV and, in some accounts, infants and children. This is precisely what bioethicist Seema Shab's contribution suggests with respect to children. In her view, experimental stem cell transplant curative strategies should not have 
been tested on children at the time they were, because the special conditions for starting particularly risky interventions in that special population were not met. Less risky interventions, such as very early ART, may have been ethical.

One of the challenges for investigators and oversight bodies in assessing the riskiness (on balance) of interventions in the HIV cure area is the high uncertainty attached to interventions never before tried in (immunocompromised) humans. In many cases, we feel as though we cannot even put a number on the precise level of risk. Philosopher Caspar Hare's contribution to this symposium offers several strategies for coping with high uncertainty in reviewing study protocols, and advises on the distinctive pitfalls and biases of each.

Among candidate solutions to a concern about benefit:risk ratio in a clinical study, reducing risk may seem like something that researchers should do anyhow, so long as scientific validity is retained. However, none of these candidate solutions is morally costless. More careful preclinical testing usually takes longer, and delays the potential succour to millions of patients: a major source of avoidable morbidity and mortality. Besides, all of these candidate solutions would leave some net risk in place, both because some uncertainty and risk are unavoidable in studies of novel strategies, and because reducing risk can come at a dire cost. All in all, to resolve the benefit:risk ratio challenge and keep early-phase HIV cure and remission studies ethical, more than risk-reduction is needed.

\section{BENEFITS TO PARTICIPANTS}

A ratio can be enhanced either by reducing its denominator or by increasing its numerator. Some conceivable moves to address the benefit:risk ratio increase the benefits numerator of that ratio, or argue that these benefits are already greater than assumed.

One candidate solution along these lines has been offered in justification of early-phase studies in other areas. It relies on the occasional clinical effect, even in early-phase trials, ${ }^{20}$ and argues that such benefits help make trial participation worthwhile on balance. ${ }^{21}$ Indeed, whereas some solutions to the benefit:risk ratio challenge reduce the cure intervention's dosage with a view to decreasing the chance for adverse events, others increase it with a view to increasing the chance for a therapeutic/curative effect that would make trial participation worthwhile. ${ }^{22} 23$

A host of other candidate solutions expound the many other potential medical benefits, direct and indirect, which (earlyphase) trial participation may facilitate. Medical research institutions can be medically more proficient than otherwise available clinical services. Post-trial access to proven study interventions may be offered. Ancillary care may be available. These and other potential medical benefits, unavailable universally, can make the 'package deal' more advantageous to participants, risk notwithstanding. In cases of last-hope patients and ones with outrageously inadequate access to basic services, medical benefits available in early-phase trials are especially likely to maximise the patient's medical prospects.

What about patients who are doing well on antiretrovirals to which they already have ready access, like many of the ones envisaged for HIV cure trials? In her contribution to the symposium, philosopher Lara Buchak defends even early-phase clinical studies of candidate HIV cure and remission interventions that do not maximise participants' prospects. Invoking her own recent work in decision theory, she questions both the notion that the only prudentially rational choice is to maximise expected utility, and the one that researchers must not recruit patients for studies with low benefit:risk ratios for them. In her view, researchers should instead defer to the considered preferences of the participants themselves, and she proposes a method of ensuring that these preferences are in line with their general attitude to risk-for example, with how risk-seeking they are in general.

A still different family of candidate solutions to the challenge involves non-medical benefits-most straightforwardly, financial and other fungible benefits-either through benefit sharing and generous compensation for burdens or adverse events or, most directly, as a fee to offset risks in advance. In her contribution to this symposium, nurse and bioethicist Emily Largent argues that offering payment in HIV cure trials is necessary in order to restore a favourable benefit:risk ratio for participants and avoid their exploitation.

A quite different non-medical benefit is the psychosocial benefit to participants that may come from helping to fightand potentially to cure-AIDS. Altruistic participants have every right to feel pride about the risk that they undertook for others' sakes. Living with HIV, they can plausibly be assumed to appreciate the importance of the cause and to draw satisfaction from fighting back against a disease that has affected them and potentially their loved ones. In their community, having acted in these heroic ways may enhance status and presumably self-esteem. (Social status and self-esteem may also rise if 'material benefits' take the form of supporting the participants' entire community or donating money to charities of their choice.) Is it always ethically wrong to rely on such psychosocial benefits to justify medical studies?

Altruistic undertakings can also be considered contributors to an objectively better life. Our life stories, and life's composite moments, affect how well our lives will have gone. ${ }^{24}$ It stands to reason that a life that contains, or even ends, with a heroic and potentially redemptive fight against a disease that has marred it is, in one key respect, better. Participation in HIV cure studies may be a classical case in point-what more heroic, more meaningful thing to do with one's life ${ }^{25}$ And if deep identification and endorsement of a project adds to its value,${ }^{26}$ then there can clearly be added value when HIV patients volunteer to fight HIV.

Such unusual justifications of risky studies through benefits other than direct medical ones may seem odd and detached. But several actual cure study participants point precisely to such benefits as having been sources of motivation for their decisions to join cure studies. AIDS activist David Evans's conversations with four HIV-positive individuals who have participated in cure studies show that in their minds at least, the non-clinical benefits they secured offset satisfactorily the risks they undertook.

Several potential moves to address the challenge of benefit: risk ratio suppress the net risk to participants by recruiting particular categories of patients with either less to lose or more to gain. One move is recruiting only patients who need the intervention anyhow, for example, to address an unrelated comorbidity. This is part of how stem cell transplants were justified in the 'Berlin patient' and the 'Boston patients' cases, all of whom needed such transplants for cancers. ${ }^{27}$ Another option is recruiting only patients with (allegedly) little to lose due to a terminal condition-again, to some degree the situation that these advanced cancer patients were at. ${ }^{27}$ Another move is recruiting only patients with (projected) poor adherence to ART-on the thought that ART provides little safety to them-if likely to adhere to the curative therapy. ${ }^{28}$ Yet another move is recruiting only patients resistant to first, second and third line ART-to whom ART is not a good-enough alternative. A further move in 
this vein is recruiting only patients without early access to ART, for example, because, unfairly, in their international locale early ART is unavailable, de jure or de facto. A final move is conducting early-phase trials on patients with terminal conditions, poor ART adherence, resistance to all ART and so on, and later phases on healthier patients; in effect, the current administrative separation between the reviews of different studies may lead precisely to that (discriminatory) result.

\section{INFORMED CONSENT}

Another category of candidate responses to the benefit:risk ratio challenge emphasises the potential, in cure and remission studies, for free and informed consent. Such consent can be relevant in two ways. First, it is one indication that participants benefit in net prospect from study participation, in ways that are very real yet opaque to oversight bodies. Second, a person's truly autonomous authorisation is usually thought to permit even many medical procedures that the person would be wise to avoid.

Admittedly, research subject protection has traditionally tended to be 'pervasively paternalistic'. ${ }^{29}$ And there do exist distinctive reasons for an added measure of soft or even hard paternalistic protection in clinical research. Still, one could argue that disallowing willing volunteers to take on adverse benefit:risk ratios when the cost is sacrifice of dramatic advances in the fight against a global epidemic is an unjustifiable degree of paternalism. In other words, it is one thing to argue.

1. Moderate paternalism I: despite the person's (autonomous) consent to Aing, the value of protecting her provides a pro tanto reason to stop her from Aing; and/or

2. Moderate paternalism I: despite the person's (autonomous) consent to Aing, the value of protecting her permits us to stop her from Aing.

It is quite another to argue that, when major medical advances require acceding to an autonomous volunteer's suggestion to let her undertake medical risk that may pay off in some way unknown to us, still we should not—-that is, to argue

3. Extreme paternalism: despite the person's (autonomous) consent to Aing, the value of protecting her provides an absolute reason to stop her from Aing-such that the study is all things considered impermissible notwithstanding its tremendous social value.

Of course, study participants are only human, and may turn out to assess the net benefits incorrectly-say, to play down the risks or play up the chance to overcome stigma and its repercussions upon being cured. They may choose non-autonomously in other ways, but this can usually be tackled through measures to increase the likelihood of autonomous choice, such as computerised repeat tests to ensure full comprehension.

Keeping candidate participants' consent autonomous is no trivial matter, though. Even after ensuring that consent forms are not misleading, ${ }^{30}$ challenges remain. Bioethicist George Annas argues that simply naming a research project based on goals ('cure') or a specific individual (eg, the 'Mississippi Baby') already tends to subvert informed consent when the name represents a 'success' - or to prematurely end a line of research if the named subject dies or is severely injured in the research. Explaining-correctly - that the study is a step toward developing a 'cure' may raise false hopes and excessive risk-taking. And some may argue that something must be wrong with any consent obtained to participate in risky studies with little direct benefit: that either the patient misunderstood risks, or she was under pressure from someone, or she lacked capacity for rational decision-making and so forth. However, the quality of consent is not generally assessed by its content-by what that consent is for. ${ }^{31} 32$ Evans's piece portrays sophisticated study participants who joined only after making repeat inquiries of the risks. Philosophically, it can be perfectly rational to choose knowingly to promote what is impartially best even at a dire cost to oneself. ${ }^{33}$ Certainly, it would be wrongheaded to ban every personal choice that compromises the chooser's selfinterest, for example, any donations and volunteering from which the donor or volunteer is likely to lose more than she gains overall-materially, psychologically, and otherwise.

In their joint contribution to the symposium, philosophers Danielle Bromwich and Joseph Millum add further nuance to the exploration of consent as a solution to the benefit:risk ratio challenge. They distinguish three separate concerns about informed consent to HIV cure research participation: about how information is communicated to potential participants; about potential participants' motivations for enrolling in potentially high-risk research with no prospect of direct benefit and about participants' understanding of the details of the trials in which they enrol. They also assess the validity of these concerns and suggest ways to address each.

\section{BENEFITS TO NON-PARTICIPANTS}

As philosopher Dan Wikler points out in his contribution, prevalent interpretations of the benefit:risk ratio requirement miss the point of the regulatory framework, particularly of US regulations governing federally funded research on human subjects. ${ }^{1}$ The benefit:risk ratio requirement in those regulations focuses on the ratio between net risks to the individual participant and benefits to society at large, and not on the ratio between risks and benefits to the same individual participant. In Wikler's view, benefits to non-participating patients belong to the balance scale too. A candidate solution in this spirit emphasises the tremendous global health value of finding a cure or durable remission strategy for HIV, and insists that value for millions of burdened individuals should enter a comprehensive benefit:risk ratio, justifying some added risk to participants. ${ }^{29}$

The effect of early-phase cure and remission studies on global health should not be exaggerated, though. Few experimental interventions in early phases of testing mature into public health improvements. And as public health expert Regina Brown and philosopher Nick Evans suggest in their contribution, in our nonideal world there is no guarantee that a safe and efficacious cure or remission strategy would translate into a real solution for the millions of people living with HIV around the globe-that depends on what society will actually do with any strategy developed, and that chance differs for different strategies, depending on cost and the means of delivery, for example. The social value of the cure therefore depends in part on a philosophical question: whether that value should reflect our shameful record of failure to roll out interventions to the millions who need them, or it should idealise our expected future performance.

The argument from benefits to non-participants can assume that social utility trumps individual rights. But research ethicists have traditionally rejected that potentially utilitarian reasoning. Philosopher Rabul Kumar's contribution argues that a demand for a favourable benefit:risk ratio for individual participants alone, regardless of the impact on others, is difficult to defend, from a utilitarian standpoint and even on Kantian contractualist grounds.

Philosopher Frances Kamm responds to Kumar, addressing several issues in relation to risks in research: (1) treating someone as a mere means; (2) aggregation; (3) different conceptions of contractualism; (4) uncertainty and (5) paternalism and complicity. 
Other non-consequentialist responses could ask whether we really have rights as individuals to avoid any depreciation in our welfare and health prospects, even when stakes are similar or higher for others, and when their prospects or realisations are worse or below 'sufficiency' level. ${ }^{34}$ Might we all have deontological duties of reciprocity as beneficiaries of past medical research to take on risks in further clinical research? ${ }^{35}$ Enforcing such duties would be very extreme. But note, finally, that in the case of early-phase cure and remission studies, study volunteers willingly consent to help. The ethics of ethical allocation of risks to people who grant permission to place them at risk is entirely different, and radically more accepting of placing people at risk for the sake of an important societal goal, than the ethics of imposing unwanted risk, which continues to haunt the imaginations of research ethicists.

\section{CONCLUSION}

This symposium expounds a wide array of candidate solutions to the challenge of apparently adverse benefit:risk ratios in some early-phase studies of HIV cure and remission strategies. The candidate solutions we review focus on four elements-risks to participants, benefits to participants, their informed consent and benefits to non-participants. While this article neither endorses nor rejects any of these candidate solutions, or any particular combination there of, the breadth of possibilities is striking.

Acknowledgements This paper was presented at the NIH Division of AIDS and at Harvard Medical School. The author is grateful to the audiences for comments and, for written comments, to Regina Brown, Steve Joffe, and Dan Wikler.

Funding This work was funded by NIAID grants 1 R01 Al114617-01A1 and 1 R56 Al114617-01, both titled 'HIV cure studies: risk, risk perception and ethics'.

Competing interests None declared.

Provenance and peer review Commissioned; internally peer reviewed.

Open Access This is an Open Access article distributed in accordance with the Creative Commons Attribution Non Commercial (CC BY-NC 4.0) license, which permits others to distribute, remix, adapt, build upon this work non-commercially, and license their derivative works on different terms, provided the original work is properly cited and the use is non-commercial. See: http://creativecommons.org/ licenses/by-nc/4.0/

\section{REFERENCES}

1 HHS. 45 CFR 46 (Human subjects research). USA, 2009.

2 National Commission for the Protection of Human Subjects of Biomedical and Behavioral Research. The Belmont report. Secondary the Belmont report. 1998. http://www.fda.gov/oc/ohrt/IRBS/belmont.html

3 Emanuel EJ, Wendler D, Grady C. What makes clinical research ethical? JAMA 2000;283:2701-11.

4 Angell M. Medical research: the dangers to the human subjects. The New York Review of Books 2015;62(18)

5 Lo B, Grady C, Working Group on Ethics of the International AIDS Society. Ethical considerations in HIV cure research: points to consider. Curr Opin HIV AIDS 2013;8:243-9.

6 Kimmelman J. Gene transfer and the ethics of first-in-human research: lost in translation. Cambridge: Cambridge UP, 2010.
7 Kimmelman J, London AJ. Predicting harms and benefits in translational trials: ethics, evidence, and uncertainty. PLoS Med 2011;8:e1001010.

8 Dresser R. First-in-human trial participants: not a vulnerable population, but vulnerable nonetheless. J Law Med Ethics 2009:37:38-50.

9 Dresser R. Building an ethical foundation for first-in-human nanotrials. J Law Med Ethics 2012:40:802-8.

10 Tighiouart M, Rogatko A, Babb JS. Flexible Bayesian methods for cancer phase I clinical trials. Dose escalation with overdose control. Stat Med 2005:24:2183-96.

11 Koyfman SA, Agrawal M, Garrett-Mayer E, et al. Risks and benefits associated with novel phase 1 oncology trial designs. Cancer 2007;110:1115-24.

12 Zohar S, O'Quigley J. Re: Dose escalation methods in phase I cancer clinical trials J Natl Cancer Inst 2009;101:1732-3; author reply 33-5.

13 Le Tourneau C, Lee JJ, Siu LL. Dose escalation methods in phase I cancer clinical trials. J Natl Cancer Inst 2009;101:708-20.

14 Chen Z, Tighiouart M, Kowalski J. Dose escalation with overdose control using a quasi-continuous toxicity score in cancer Phase I clinical trials. Contemp Clin Tria/s 2012;33:949-58

15 Shah SK, Persaud D, Wendler DS, et al. Research into a functional cure for HIV in neonates: the need for ethical foresight. Lancet Infect Dis 2014; 14:893-8.

16 Leventhal J, Abecassis M, Miller J, et al. Chimerism and Tolerance Without GVHD or engraftment syndrome in HLA-mismatched combined kidney and hematopoietic stem cell transplantation. Sci Trans/ Med 2012;4:124ra28.

17 Persaud D, Gay H, Ziemniak C, et al. Absence of detectable HIV-1 viremia after treatment cessation in an infant. N Engl J Med 2013;369:1828-35.

18 Purcell DF, Elliott JH, Ross AL, et al. Towards an HIV cure: science and debate from the International AIDS Society 2013 symposium. Retrovirology 2013;10:134

19 Lo YR, Chu C, Ananworanich J, et al. Stakeholder Engagement in HIV Cure Research: Lessons Learned from Other HIV Interventions and the Way Forward. AIDS Patient Care STDS 2015;29:389-99.

20 Kurzrock R, Benjamin RS. Risks and benefits of phase 1 oncology trials, revisited. New Engl J Med 2005;352:930-2.

21 Miller FG, Joffe S. Benefit in phase 1 oncology trials: therapeutic misconception or reasonable treatment option? Clin Trials 2008;5:617-23.

22 Agrawal M, Emanuel EJ. Phase I oncology research. In: Emanuel EJ, Grady C, Crouch RA, et al, eds. The Oxford textbook of clinical research ethics. Oxford: Oxford UP, 2006:356-66.

23 Hey SP, Kimmelman J. The risk-escalation model: a principled design strategy for early-phase trials. Kennedy Inst Ethics J 2014;24:121-39.

24 Velleman JD. Well-being and time. Pac Philos Q 1991;72:48-77.

25 Wendler DS. The Ethics of pediatric research. New York: Oxford University Press, 2010.

26 Dworkin R. What is equality? Part 1: equality of welfare. Philos Public Aff 1981;10:185-246.

27 Hayden EC. Bid to cure HIV ramps up. Nature 2013;498:417-18.

28 Shah SK, Persaud D, Wendler DS, et al. Research on a cure for HIV in neonates: the need for ethical foresight. 2013 IMPAACT Leadership Retreat. Washington DC, 2013.

29 Miller FG, Wertheimer A. Facing up to paternalism in research ethics. Hastings Cent Rep 2007;37:24-34

30 Henderson GE. The ethics of HIV "cure" research: what can we learn from consent forms? AIDS Res Hum Retroviruses 2015;31:56-63.

31 Dworkin G. The theory and practice of autonomy. Cambridge: Cambridge University Press, 1988.

32 Appelbaum PS. Clinical practice. Assessment of patients' competence to consent to treatment. N Engl J Med 2007;357:1834-40.

33 Parfit D. On what matters. 1st edn. New York: Oxford UP, 2013.

34 Fabre C. Whose body is it anyway? Justice and the integrity of the person. Oxford: Oxford University Press, 2008

35 Harris J. Scientific research is a moral duty. J Med Ethics 2005;31:242-8. 